\title{
A Semiactive and Adaptive Hybrid Control System for a Tracked Vehicle Hydropneumatic Suspension Based on Disturbance Identification
}

\author{
Shousong Han, Zhiqiang Chao, and Xiangbo Liu \\ Department of Mechanical Engineering, Academy of Armored Forces, Beijing 100072, China \\ Correspondence should be addressed to Shousong Han; hssbeijing@163.com
}

Received 6 June 2017; Revised 31 August 2017; Accepted 17 September 2017; Published 18 October 2017

Academic Editor: Mario Terzo

Copyright (C) 2017 Shousong Han et al. This is an open access article distributed under the Creative Commons Attribution License, which permits unrestricted use, distribution, and reproduction in any medium, provided the original work is properly cited.

\begin{abstract}
The riding conditions for a high-speed tracked vehicle are quite complex. To enhance the adaptability of suspension systems to different riding conditions, a semiactive and self-adaptive hybrid control strategy based on disturbance velocity and frequency identification was proposed. A mathematical model of the semiactive, self-adaptive hybrid suspension control system, along with a performance evaluation function, was established. Based on a two-degree-of-freedom (DOF) suspension system, the kinematic relations and frequency zero-crossing detection method were defined, and expressions for the disturbance velocity and disturbance frequency of the road were obtained. Optimal scheduling of the semiactive hybrid damping control gain $\left(c_{\text {sky }}, c_{\text {ground }}, c_{\text {hybrid }}\right)$ and selfadaptive control gain $\left(c_{v}\right)$ under different disturbances were realized by exploiting the particle swarm multiobjective optimization algorithm. An experimental study using a carefully designed test rig was performed under a number of typical riding conditions of tracked vehicles, and the results showed that the proposed control strategy is capable of accurately recognizing different disturbances, shifting between control modes (semiactive/self-adaptive), and scheduling the damping control gain according to the disturbance identification outcomes; hence, the proposed strategy could achieve a good trade-off between ride comfort and ride safety and efficiently increase the overall performance of the suspension under various riding conditions.
\end{abstract}

\section{Introduction}

The driving conditions for high-speed tracked vehicles are harsh and varied. With the adoption of a damping adjustable suspension system, not only can the vibration performance of a vehicle be improved, the average off-road speed can also be substantially improved, thereby enhancing the motility and effectiveness of the vehicle [1]. Semiactive hydropneumatic suspensions take the vibration status of a vehicle as input, schedule the system damping in real-time according to a certain control algorithm, and, in turn, improve ride comfort and safety during driving. The selection of the damping control algorithm and control gain will directly determine the performance of the suspension dynamics $[2,3]$.

Many methodologies have been used to design semiactive suspension control systems. A controller based on the skyhook theory was developed by Emura [4]. An observerbased control methodology which can estimate the vertical velocities of the vehicle body and the wheel by using the acceleration of the vehicle body was proposed by Yi [5]. An MR damper implemented by the skyhook, groundhook, and the hybrid strategies was tested on a quarter-car rig [6]. It showed that the skyhook algorithm can significantly attenuate the sprung mass acceleration while the groundhook can improve the road holding ability. Reference [7] proposed a novel model-free control strategy named Combinatory quasi-Optimum Damping (COD) Controller which can optimize damping force of the tunable dampers. Some other modern methodologies have also been widely proposed to improve the performance of controller, such as the modelbased control strategies by using robust [8-10], nonlinear [11, 12], and optimal control theory [13]. Heuristic control methodologies have good performances with high feasibility to be implemented if the accurate vehicle mathematic model or the observer is not available [14-16].

For a multiwheel tracked vehicle, the track has a certain attenuation effect on high-frequency road excitations which can reduce the high-frequency vibration of the vehicle body. 


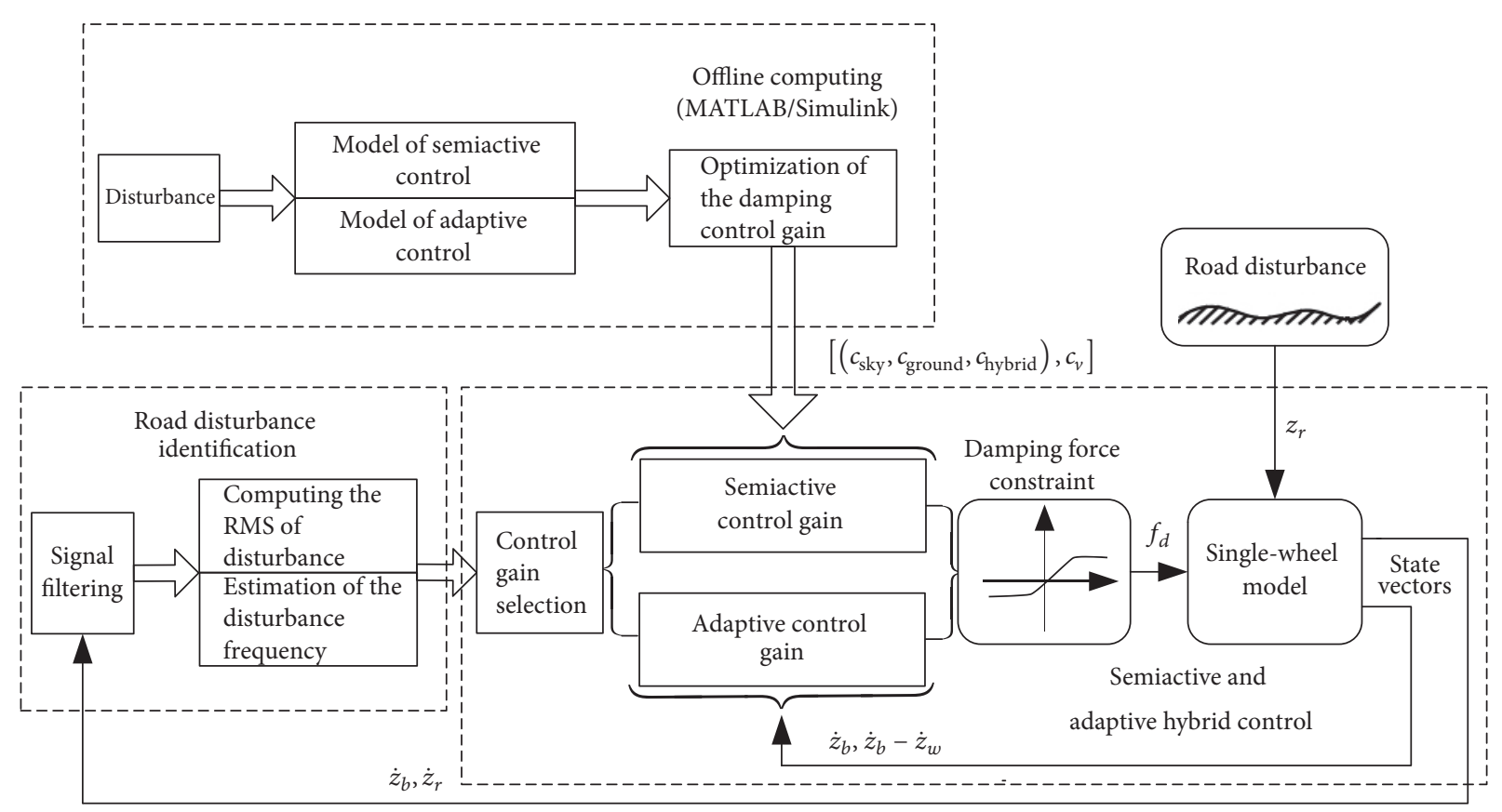

Figure 1: Hybrid control strategy of the suspension based on disturbance identification.

Therefore, in the mathematic analysis of ride comfort, the influence on ride comfort of the track can be ignored [17]. However, different from wheeled vehicles, the special structure of the track and its interactions with the running system bring new problems to the ride safety of high mobility tracked vehicles, for example, track separating from the wheels. Reference [18] showed that the high dynamic load of the wheel will cause some individual wheels to lift off from the track tread and may result in safety problems. Meanwhile, the inadequate contact force between the wheel and track tread may also cause the turning controllability of the vehicle decrease. In terms of the semiactive control algorithm of the tracked vehicle, most studies care only about the improvement of the ride comfort [19-21]. The problems such as the reasonable control between the ride comfort and safety and optimum scheduling of the damping control gain under different disturbances are waiting to be solved.

For all kinds of vehicle suspension systems, the input disturbance comes from the road. In order to enhance adaptability, the combination of suspension control and road excitation identification is key and a central theme in current research on damping tunable suspensions. This paper proposes a semiactive self-adaptive hybrid control strategy for a tracked vehicle with a hydropneumatic suspension. The proposed strategy takes advantage of the adaptability of the suspension control algorithm and damping control gain scheduling under different road excitations. First of all, the identification of the disturbance velocity and frequency was fulfilled based on the suspension kinematic analysis and frequency zero-crossing detection method. Different damping control gains were optimized offline by exploiting the PSO algorithm and then implemented online by lookup tables.
Experimental study of typical control strategies was performed and the results showed that the proposed control strategy outperforms the others in achieving a good tradeoff between the ride comfort and safety under various riding conditions.

\section{Hybrid Control Strategy}

The structural framework of the semiactive self-adaptive hybrid control strategy for the suspension system based on disturbance identification is illustrated in Figure 1. The control strategy is comprised of two parts: the offline part finds a solution to the optimized control gain, and the online part is responsible for control model selection and gain adjustment. The offline part can find a solution for the corresponding optimal control gain for different disturbances, whereas the online control component identifies the disturbance frequency and velocity according to the suspension status and then selects the control mode and schedules the optimized damping control gains according to the identification results; therefore, the system's adaptability is improved for a wide-range (frequency and velocity) of excitations and a good trade-off between ride comfort and ride safety can be achieved.

\section{Single-Wheel Suspension Model}

3.1. Hybrid Control Mathematical Model and Control Mode Selection. The "quarter vehicle model" contains all the major characteristics of a suspension system. A single-wheel suspension system with a tunable damper was studied in this 


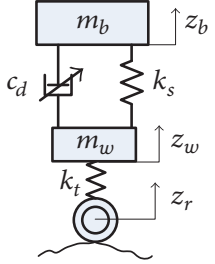

(a)

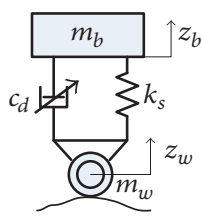

(b)
FIgURE 2: The single-wheel suspension model.

paper, as presented in Figure 2(a). As the rubber rings of the road wheel of tracked vehicles are relatively thin with high rigidity, distortion of the rubber rings can be neglected such that the elevation of the road $z_{r}$ can be regarded as identical to the vertical displacement of the road wheel $z_{w}$. The single-wheel equivalent model is shown in Figure 2(a) and can be further simplified by applying an order reduction to the model, displayed in Figure 2(b).

The kinematic model of a single-wheeled suspension system (Figure 2(b)) yields the following equations:

$$
\begin{gathered}
m_{b} \ddot{z}_{b}+k_{s}\left(z_{b}-z_{w}\right)+f_{d}=0, \\
m_{w} \ddot{z}_{w}+k_{s}\left(z_{w}-z_{b}\right)-f_{d}=0,
\end{gathered}
$$

where the selection of $f_{d}$ can be divided into two cases.

(1) When the disturbance frequency is smaller than onefifth of the damping control bandwidth [22], a semiactive control mode is adopted. In principle, the single skyhook control is only capable of improving ride comfort while reducing ride safety. Conversely, groundhook control reduces ride comfort while improving ride safety. Therefore, to achieve a trade-off between comfort and safety, the semiactive control model adopts a hybrid control strategy using both skyhook and groundhook, whereby the control algorithm can be defined as follows:

$$
\begin{aligned}
& f_{d} \\
& = \begin{cases}c_{\text {hybrid }}\left(\dot{z}_{b}-\dot{z}_{w}\right), & \dot{z}_{b}\left(\dot{z}_{b}-\dot{z}_{w}\right) \geq 0, \dot{z}_{w}\left(\dot{z}_{b}-\dot{z}_{w}\right) \leq 0 ; \\
c_{\text {sky }}\left(\dot{z}_{b}-\dot{z}_{w}\right), & \dot{z}_{b}\left(\dot{z}_{b}-\dot{z}_{w}\right) \geq 0, \dot{z}_{w}\left(\dot{z}_{b}-\dot{z}_{w}\right)>0 ; \\
c_{\text {ground }}\left(\dot{z}_{b}-\dot{z}_{w}\right), & \dot{z}_{b}\left(\dot{z}_{b}-\dot{z}_{w}\right)<0, \dot{z}_{w}\left(\dot{z}_{b}-\dot{z}_{w}\right) \leq 0 ; \\
c_{\text {min }}\left(\dot{z}_{b}-\dot{z}_{w}\right), & \dot{z}_{b}\left(\dot{z}_{b}-\dot{z}_{w}\right)<0, \dot{z}_{w}\left(\dot{z}_{b}-\dot{z}_{w}\right)>0 .\end{cases}
\end{aligned}
$$

$c_{\text {sky }}$ and $c_{\text {ground }}$ represent the skyhook and groundhook damping coefficients, respectively, $c_{\min }$ is the minimum damping coefficient, which is zero in ideal conditions, and $c_{\text {hybrid }}$ is the hybrid damping coefficient, which can be expressed by

$$
c_{\text {hybrid }}=\beta c_{\text {sky }}+(1-\beta) c_{\text {ground }},
$$

where $\beta$ is a coefficient between 0 and 1 . When $\beta=1, c_{\text {hybrid }}$ is $c_{\text {sky }}$ and when $\beta=0$, $c_{\text {hybrid }}$ is $c_{\text {ground }}$.

(2) When the disturbance frequency is higher than or equivalent to one-fifth of the damping control bandwidth, a time delay caused by tuning the damping accounts for a large proportion of the suspension vibration period and a selfadaptive control mode is adopted. The damping control gain is self-tuned with respect to the statistical characteristics of the disturbances and no longer adjusted during the single vibration period of the suspension. The control algorithm is expressed as follows:

$$
f_{d}=c_{v}\left(\dot{z}_{b}-\dot{z}_{w}\right)
$$

where $\dot{z}_{b}$ and $\dot{z}_{w}$ represent the vertical velocities of the sprung and unsprung mass, respectively, and $c_{v}$ is the damping coefficient under the self-adaptive control mode.

3.2. Performance Evaluation Index of Suspensions. The performance evaluation indices of a vehicle suspension system mainly include the sprung mass acceleration, wheel dynamic load, and suspension stroke. Taking the vertical disturbance velocity from the road as input, the transfer function of the aforementioned indices can be solved as follows:

(1) The transfer function $H(s)_{\ddot{z}_{b} \sim \dot{z}_{r}}$ of the sprung mass acceleration:

$$
H(s)_{\ddot{z}_{b} \sim \dot{z}_{r}}=\frac{c s^{2}+k_{s} s}{m_{b} s^{2}+c s+k_{s}} .
$$

(2) The transfer function $H(s)_{z_{s} \sim \dot{z}_{r}}$ of the suspension stroke:

$$
H(s)_{z_{s} \sim \dot{z}_{r}}=\frac{-m_{b} s}{m_{b} s^{2}+c s+k_{s}}
$$

where $z_{s}$ is the suspension stroke.

(3) The dynamic load $F_{D}$ acting on the wheel can be expressed as

$$
F_{D}=F_{C}-F_{S}
$$

where $F_{C}$ is the contact force between the wheel and the track which is sum of the wheel acceleration force and the suspension acting force and $F_{S}$ is the wheel static contact force which is approximately the weight of the sprung and unsprung mass.

The transfer function $H(s)_{\ddot{z}_{w} \sim \dot{z}_{r}}$ from the road disturbance velocity to the wheel acceleration is

$$
H(s)_{\ddot{z}_{w} \sim \dot{z}_{r}}=s .
$$

Then the transfer function $H(s)_{F_{C} \sim \dot{z}_{r}}$ of the contact force between the wheel and the track is

$$
H(s)_{F_{C} \sim \dot{z}_{r}}=s\left(m_{w}+m_{b} \frac{c s+k_{s}}{m_{b} s^{2}+c s+k_{s}}\right) .
$$

\section{Identifications of Disturbance Characteristics}

4.1. Disturbance Velocity. According to the kinematic relationship of the two-degree-of-freedom (DOF) suspension system, we have

$$
z_{r}=z_{b}-z_{s}
$$




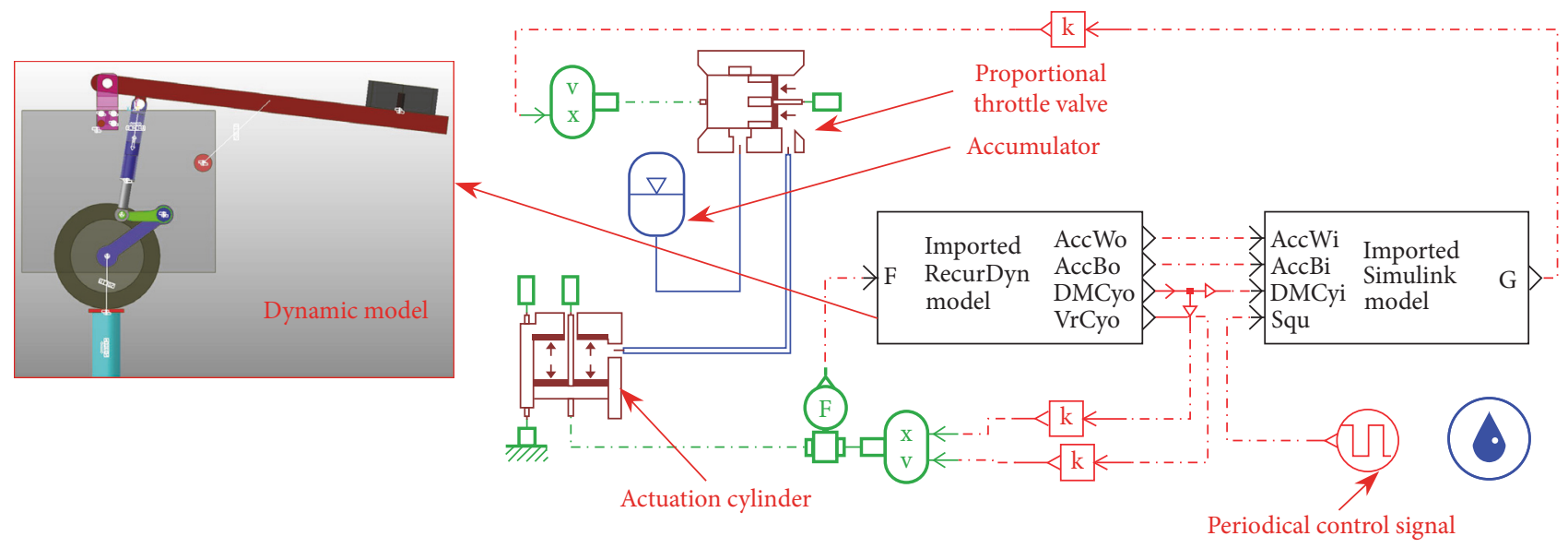

FIGURE 3: Cosimulation model of single-wheel suspension.

Taking derivatives on both sides of the equation, the disturbance velocity $\dot{z}_{r}$ can be obtained as

$$
\dot{z}_{r}=\dot{z}_{b}-\dot{z}_{s}
$$

where the vertical velocity $\dot{z}_{b}$ of the sprung mass and the suspension dynamic speed $\dot{z}_{s}$ can be solved by integrating the acceleration sensor signal of the vehicle body and differentiating the sensor signal of the suspension stroke, respectively. In order to acquire a more accurate value for the vertical speed of the sprung mass, it is necessary to filter the signals so as to reduce the influence of accumulated errors from the acceleration sensor [23].

4.2. Disturbance Frequency. Based on disturbance velocity, the zero-crossing method can be applied to estimate the main frequency of the disturbance signals [24]. The firstorder main frequency of a system can be estimated by detecting three consecutive zero-crossings. In order to make the frequency estimation more precise, the moment of the zero signal crossing is obtained by interpolation based on time sampling points on either side of the zero point [25]. The frequency estimation is expressed as follows:

$$
f=\frac{1}{T_{b}-T_{a}},
$$

where $T_{a}$ is the time of the first zero-crossing and $T_{b}$ is the time of the third zero-crossing.

\section{Optimization of the Control Gain Based on the PSO Algorithm}

5.1. Selection of the Control Objective Function. In general, the damping of adjustable suspensions leads to an improvement in the performance of one index while worsening the performance of other indices; therefore, the adjustment of the damping control gain should follow the principle of achieving an optimal comprehensive index. For the suspension system, the control objective function of the overall performance can be expressed as

$$
J=\rho_{b} \ddot{z}_{b}^{2}+\rho_{s}\left(z_{b}-z_{w}\right)^{2}+\rho_{w} F_{D}^{2},
$$

where $\rho_{b}, \rho_{s}$, and $\rho_{w}$ represent the weighting factors of the sprung mass acceleration, suspension stroke, and road wheel dynamic load, respectively. These weighting factors are chosen according to the relative importance of ride comfort and safety.

In the paper, the PSO algorithm is used to obtain optimal values for the semiactive hybrid control gains $\left(c_{\text {sky }}, c_{\text {ground }}\right.$, $\left.c_{\text {hybrid }}\right)$ and self-adaptive control gain $\left(c_{v}\right)$ that will result in the minimum objective function value under different disturbances. The function (13) represents an instant objective function. At each PSO interaction step, a set of optimized damping control gains from last interaction were injected and the instant value of the function is computed and compared with the previous values. A new generation of damping control gains is generated according to the PSO algorithm and will be used for the next step. The interaction continues till the minimum function value is obtained or the maximum interaction steps are reached.

5.2. Optimization Approach. For the semiactive hydropneumatic suspension, during one vibration period the damping coefficient changes according to the vibration status of the suspension, such that the expression of the damping force is a multisection function. This results in difficulty for evaluating the overall performance of the suspension by using a mathematical modelling approach. The approach adopted herein integrates multibody dynamic software (RecurDynV8R3 [26]) to construct a kinematic model of the hydropneumatic suspension. The hydropneumatic system was developed using Lab AMESim14.0 [27] and MATLAB/Simulink was used to program the PSO algorithm in order to perform the optimization of the damping control gains. The operational interface for the multisystem cosimulation is shown in Figure 3.

To optimize the damping control gains, the input, output, sampling points, and parameters of the PSO algorithm of the control module need to be determined. The inputs are 


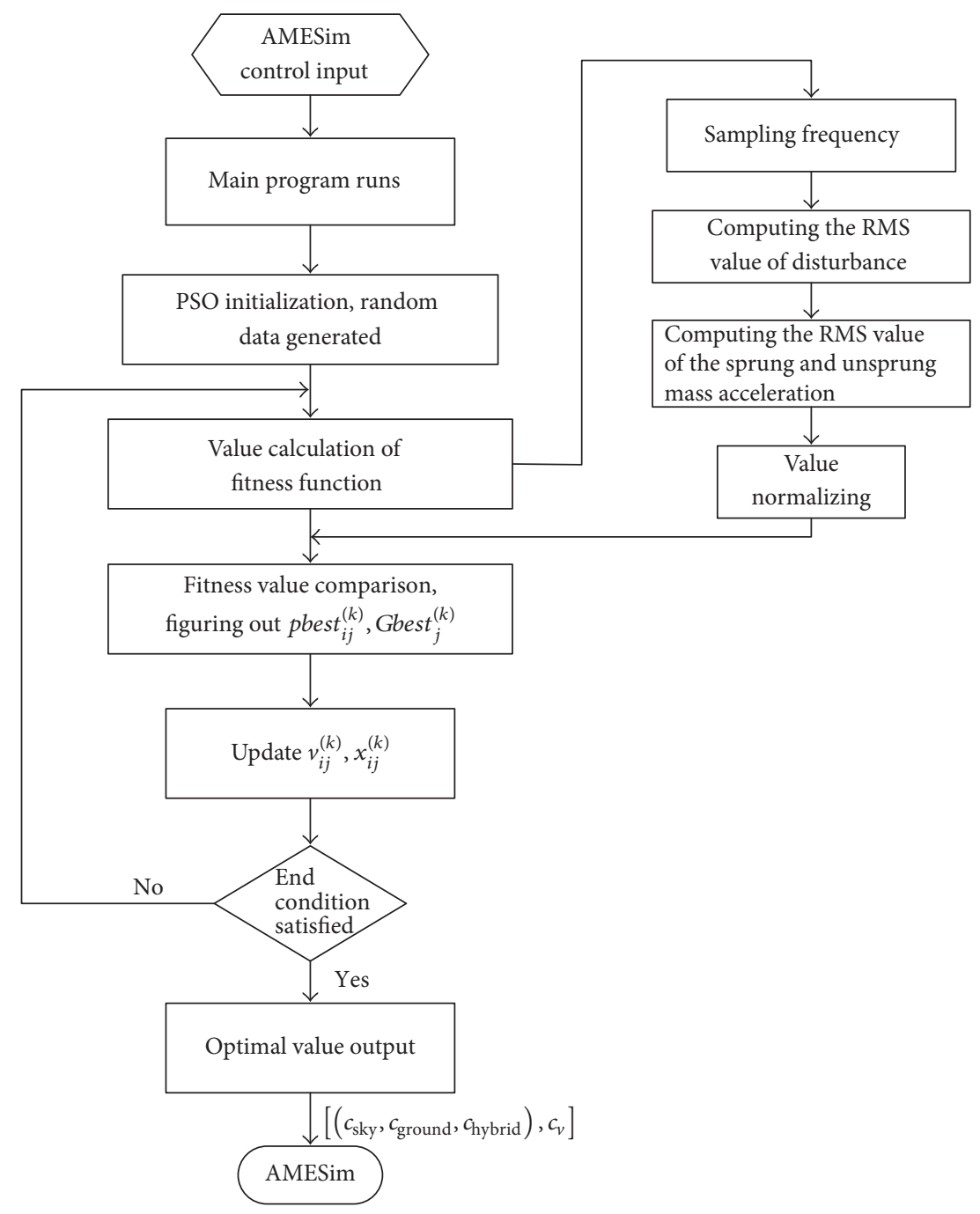

FIGURE 4: Flowchart of PSO algorithm.

the statistical values of the suspension performance indices within one control period from AMESim and the output is the damping control gain.

The program diagram of the PSO is depicted in Figure 4. The PSO program was executed under the control of the AMESim periodical signal in order to ensure correct transmission of data between the acquisition system and PSO optimization. Then, the optimized damping gain was fed back to AMESim to perform real-time adjustment to the opening of the throttle valve.

Figure 5 displays the PSO algorithm and control model established using MATLAB/Simulink, which mainly comprises the PSO algorithm (green), damping control (yellow), disturbance velocity estimation and its root mean square calculation (blue), and disturbance frequency estimation (pink) modules. The damping control module was executed according to (2) and (4), and the velocities and positions of the PSO particles were updated according to the following equations [28]:

$$
\begin{aligned}
v_{i j}^{(k+1)}= & \omega v_{i j}^{(k)}+c_{1} r_{1}\left(\text { pbest }_{i j}^{(k)}-x_{i j}^{(k)}\right) \\
& +c_{2} r_{2}\left(\text { Gbest }_{j}^{(k)}-x_{i j}^{(k)}\right), \\
x_{i j}^{(k+1)}= & x_{i j}^{(k)}+v_{i j}^{(k+1)},
\end{aligned}
$$

where $k$ is the number of iterations, $x_{i j}^{(k)}$ is the current location of particle $i, v_{i j}^{(k)}$ represents the current $j$-dimensional flying velocity of particle $i, \omega$ is the inertia factor, $c_{1}$ and $c_{2}$ are the acceleration constants, $r_{1}$ and $r_{2}$ represent random numbers within a $[0,1]$ interval, pbest ${ }_{i j}^{(k)}$ is the best possible location that particle $i$ encounters, and $G b e s t_{j}^{(k)}$ is the best location encountered among all the particles in the swarm.

\subsection{Results of the Optimization}

5.3.1. Setting the Parameters. To obtain the optimized damping control gains under different disturbances, sinusoidal 


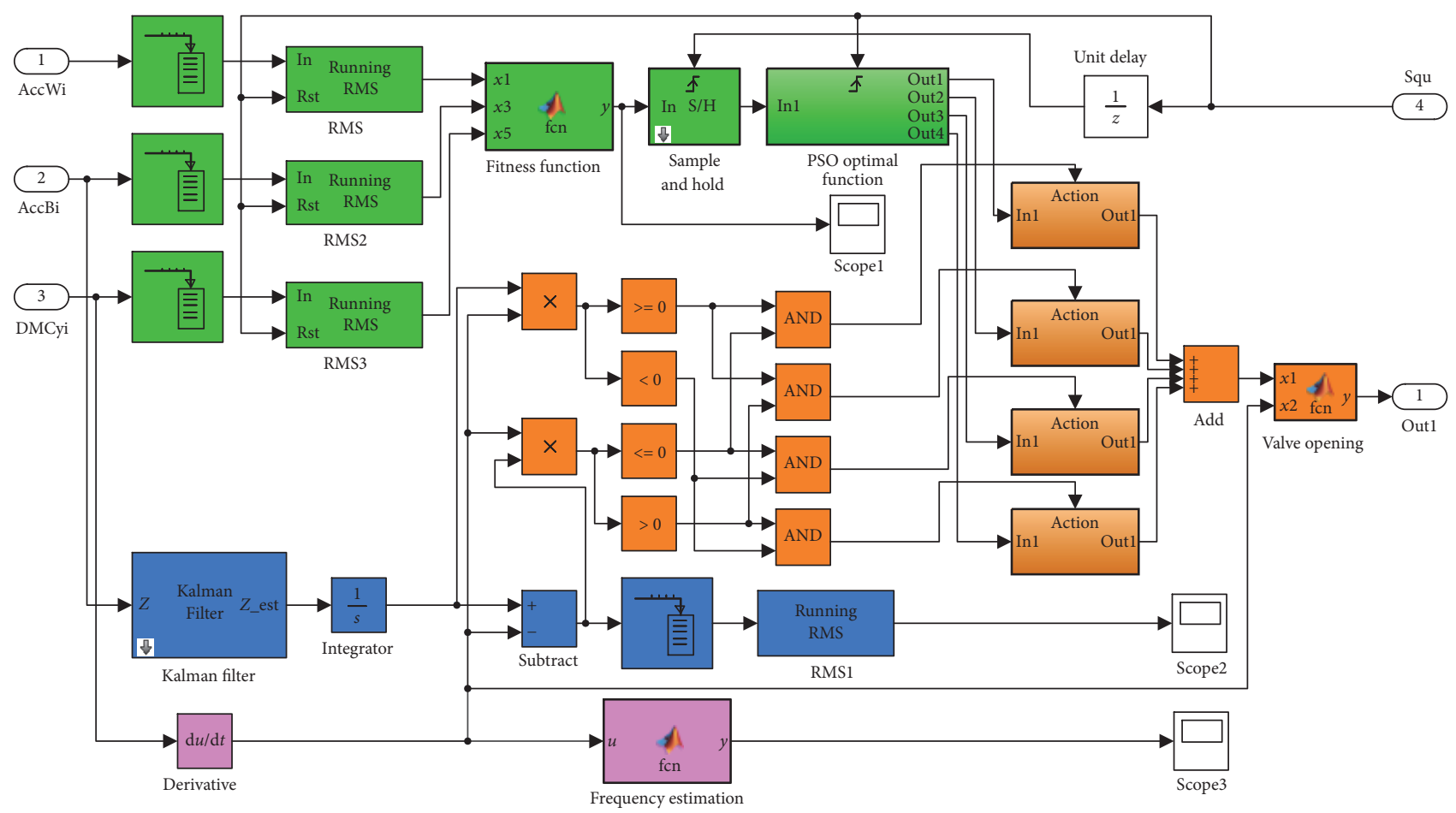

FIGURE 5: Flowchart of Simulink model using the PSO algorithm and control algorithm.

disturbance signals of various frequencies and amplitudes were set up in the RecurDyn model. The periodic control signal in AMESim was adjusted according to the disturbance frequencies. Here, it was set as 5 times the cycle time of the disturbance to allow accurate statistical computing of the output performance and suspension status. In the Simulink model, there exist continuous and discrete-time block. The sample time of the continuous block is infinitely small, but for the discrete-time block it is definite. In order to make them work at identical step, the system running frequency was set as $100 \mathrm{~Hz}$. The parameters of the two-DOF single-wheel suspension system model and initial parameter values of the PSO algorithm are displayed in Tables 1 and 2, respectively.

5.3.2. Weight Allocation. The damping coefficients are optimized based on the weighting of the suspension evaluation indices which are set according to the frequency regions and velocity grades of the road disturbance, such that the suspension can achieve a good trade-off between ride comfort and safety.

To improve ride comfort, it is important to suppress the resonant peak to within $1 \mathrm{~Hz}$ of the sprung mass acceleration because this frequency region contains the natural frequency of the sprung mass. On the other hand, it has been proven that some parts of the body, such as the stomach and eyeball, have a natural frequency between 4 and $8 \mathrm{~Hz}[29,30]$, referred to as human body frequency regions. Vibrations of the body part will occur if the frequency of the road disturbance is within this region. Higher frequency vibrations $(>20 \mathrm{~Hz})$, which could cause resonance of some objects, such as a gun or steering wheel [31], are not within the scope of this
TABLE 1: Initial values of single-wheel suspension.

\begin{tabular}{|c|c|c|c|}
\hline Variables & Symbol & Unit & Value \\
\hline Sprung mass & $m_{b}$ & $\mathrm{~kg}$ & $2.4 \times 10^{3}$ \\
\hline Unsprung mass & $m_{w}$ & $\mathrm{~kg}$ & 85 \\
\hline $\begin{array}{l}\text { Initial charge pressure of } \\
\text { the accumulator }\end{array}$ & $p_{0}$ & $\mathrm{~Pa}$ & $6.8 \times 10^{6}$ \\
\hline Volume of the accumulator & $V_{0}$ & $\mathrm{~m}^{3}$ & $0.85 \times 10^{-3}$ \\
\hline $\begin{array}{l}\text { Section area of the } \\
\text { actuation cylinder }\end{array}$ & $A_{s}$ & $\mathrm{~m}^{2}$ & $4.4 \times 10^{-3}$ \\
\hline $\begin{array}{l}\text { Lower limit of the damping } \\
\text { coefficient }\end{array}$ & $c_{\min }$ & $\mathrm{kNs} / \mathrm{m}$ & 0.6 \\
\hline $\begin{array}{l}\text { Higher limit of the } \\
\text { damping coefficient }\end{array}$ & $c_{\max }$ & $\mathrm{kNs} / \mathrm{m}$ & 25.0 \\
\hline $\begin{array}{l}\text { Bandwidth of the damping } \\
\text { control system }\end{array}$ & $B$ & $\mathrm{~Hz}$ & 42 \\
\hline
\end{tabular}

TABLE 2: Initial parameter settings of PSO algorithm.

\begin{tabular}{lccc}
\hline Variables & Symbol & Unit & Value \\
\hline Number of particles & $N$ & - & 4 \\
Particle dimensions & $D$ & - & $3 / 1$ \\
Acceleration factor 1 & $c_{1}$ & - & 2 \\
Acceleration factor 2 & $c_{2}$ & - & 2 \\
Inertia factor & $\omega$ & - & 0.7 \\
Iteration steps & $k$ & - & 20 \\
\hline
\end{tabular}

paper. For improving ride safety, the road wheels should be kept in as close contact as possible with the track to avoid 
TABLE 3: Weighting factors for different disturbances.

\begin{tabular}{|c|c|c|c|c|}
\hline \multirow{3}{*}{ Velocity grades $\left(v_{\mathrm{RMS}} / \mathrm{m} \cdot \mathrm{s}^{-1}\right)$} & \multicolumn{4}{|c|}{ Weighting factor $\left(\rho_{b}, \rho_{s}, \rho_{w}\right)$} \\
\hline & \multirow{2}{*}{$\begin{array}{c}f_{v} \\
0-4 \mathrm{~Hz}\end{array}$} & \multicolumn{2}{|c|}{$f_{h}$} & \multirow{2}{*}{$\begin{array}{c}f_{w} \\
8-16 \mathrm{~Hz}\end{array}$} \\
\hline & & $4-6 \mathrm{~Hz}$ & $6-8 \mathrm{~Hz}$ & \\
\hline Good $(v \leq 0.1)$ & $(0.9,0.05,0.05)$ & $(0.85,0.1,0.05)$ & $(0.8,0.1,0.1)$ & $(0.75,0.1,0.15)$ \\
\hline Average $(0.1<v \leq 0.3)$ & $(0.8,0.15,0.05)$ & $(0.7,0.2,0.1)$ & $(0.6,0.2,0.2)$ & $(0.5,0.2,0.3)$ \\
\hline Poor $(0.3<v \leq 0.5)$ & $(0.7,0.2,0.1)$ & $(0.6,0.25,0.15)$ & $(0.4,0.3,0.3)$ & $(0.3,0.3,0.4)$ \\
\hline Very poor $(0.5<v)$ & $(0.6,0.25,0.15)$ & $(0.5,0.3,0.2)$ & $(0.2,0.4,0.4)$ & $(0.1,0.4,0.5)$ \\
\hline
\end{tabular}

separation of the wheels and track, particularly around the natural frequency of the wheel, approximately $18 \mathrm{~Hz}$ for a tracked vehicle hydropneumatic suspension [32].

Using the values listed in Table 1, the natural frequencies of the sprung and unsprung masses were calculated as $1.2 \mathrm{~Hz}$ and $15.4 \mathrm{~Hz}$, respectively. To implement the control strategy, the frequency regions of the road disturbances were defined as follows: the vehicle-body frequency region $f_{v}=[0-4] \mathrm{Hz}$; the human body frequency region $f_{h}=[4-8] \mathrm{Hz}$; the road wheel frequency region $f_{w}=[8-16] \mathrm{Hz}$. The velocity grades are classified as "Good" $\left(v_{\mathrm{RMS}} \leq 0.1\right)$, "Average" $(0.1<$ $\left.v_{\text {RMS }} \leq 0.2\right)$, "Poor" $\left(0.3<v_{\text {RMS }} \leq 0.5\right)$, and "Very poor" $\left(0.5<v_{\mathrm{RMS}}\right)$, based on the root mean square (RMS) value of the disturbance velocity [33].

The rules for weight allocation are as follows: under the same disturbance velocity grade, when the frequency is close to the natural frequency of the vehicle body great attention should be paid to the improvement of ride comfort; when the frequency approaches the natural frequency of the wheel, the emphasis should be on suppression of the wheel dynamic load and suspension stroke [34]. Under the same disturbance frequency, when the RMS value of the disturbance velocity is relatively large, indicating road smoothness has deteriorated and the dynamic load of the wheel and the probability of end-stop occurring increases, so the weighting on ride safety should be set higher; when the disturbance velocity is relatively small, the emphasis should be on the improvement of ride comfort.

The results of incorporating weighting factors with respect to the disturbance frequencies and velocity grades are displayed in Table 3. From the optimized solution, the semiactive hybrid control gains $\left(c_{\text {sky }}, c_{\text {ground }}, c_{\text {hybrid }}\right)$ and the self-adaptive control gain $\left(c_{v}\right)$ were obtained and are displayed in Figure 6.

\section{Experimental Analysis and Results}

A test rig for the hydropneumatic suspension was used to perform an experimental study of the proposed control strategy and thus verify its feasibility. The test rig was structured with a hydraulic vibration exciter, road wheel, actuation cylinder, proportional throttle valve, and accumulator, as illustrated in Figure 7. The sprung and unsprung mass acceleration sensors had a measurement range of $\pm 5 \mathrm{~g}$ and $\pm 50 \mathrm{~g}$, respectively, and the stroke sensor had a measurement range of $\pm 200 \mathrm{~mm}$.
TABLE 4: Different roads classification.

\begin{tabular}{lccc}
\hline \multirow{2}{*}{ Road class } & \multicolumn{3}{c}{$G\left(n_{0}\right) \times 10^{-6} /\left(\mathrm{m}^{2} / \mathrm{m}^{-1}\right)$} \\
Lower limit & Geometric mean value & Upper limit \\
\hline A & 8 & 16 & 32 \\
B & 32 & 64 & 128 \\
C & 128 & 256 & 512 \\
D & 512 & 1024 & 2048 \\
E & 2048 & 4096 & 8192 \\
F & 8192 & 16384 & 32768 \\
G & 32768 & 65536 & 131072 \\
H & 131072 & 262144 & 524228 \\
\hline
\end{tabular}

6.1. Installment and Identification of Disturbance. The input disturbance is determined by the road class and vehicle speed. Road roughness coefficient is an evaluation index which determines the road class. The following formula is used as the fitting expression of the power spectral density function of the international standard road:

$$
G_{q}(n)=G_{q}\left(n_{0}\right)\left(\frac{n}{n_{0}}\right)^{-\omega},
$$

where $n$ is the spatial frequency $\left(\mathrm{m}^{-1}\right), n_{0}$ is the reference spatial frequency $\left(0.1 \mathrm{~m}^{-1}\right), G_{q}\left(n_{0}\right)$ is the road power spectrum value at the reference spatial frequency, also called the road roughness coefficient $\left(\mathrm{m}^{2} / \mathrm{m}^{-1}=\mathrm{m}^{3}\right)$, and $\omega$ is the frequency index which is the diagonal slope in a double logarithmic coordinate axis $[35,36]$.

According to the international standard, the classification of different roads is shown in Table 4.

Since most driving conditions of tracked vehicle are relatively harsh, the vibration exciter is actuated to simulate the excitations of driving on $\mathrm{D}, \mathrm{F}$, and $\mathrm{H}$ road at different speeds. The imposed disturbance signals and their estimated values are displayed in Figure 8. The statistic and estimated values of the disturbance as well as the optimized damping control gains are presented in Table 5. The system was seen to identify the disturbance velocity and frequency of the driving conditions quite well.

6.2. Results and Analysis. Figures 9-11 illustrate the contrasts between sprung mass acceleration, road wheel dynamic load, and suspension stroke by adopting four typical control 


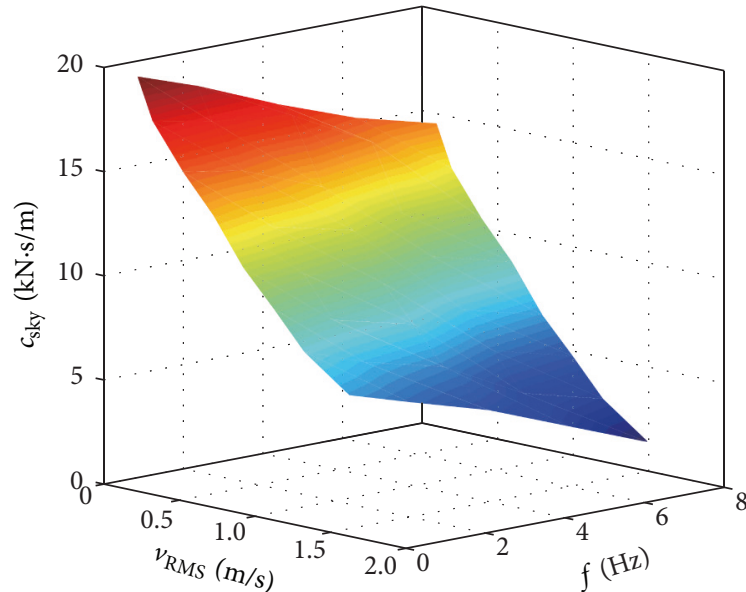

(a)

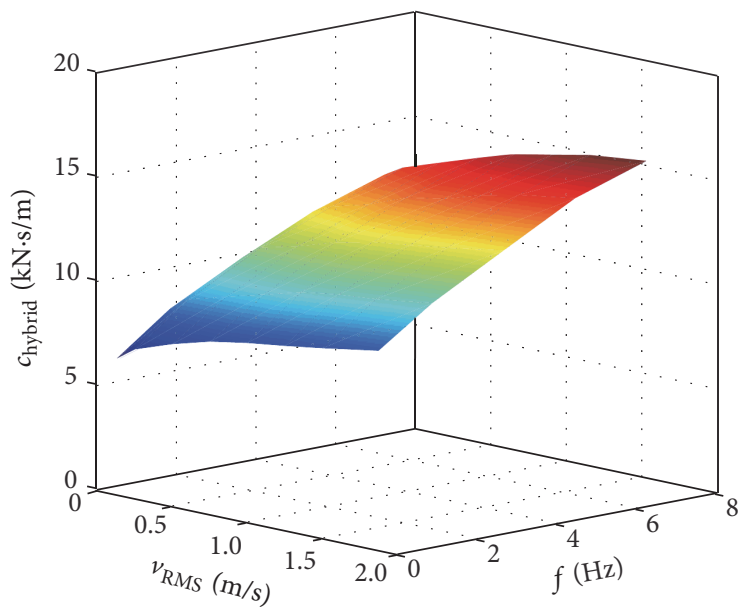

(c)

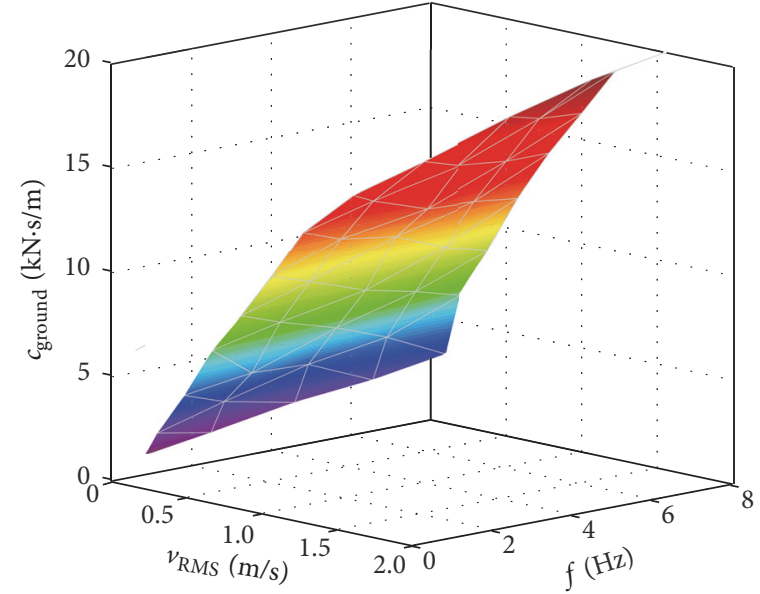

(b)

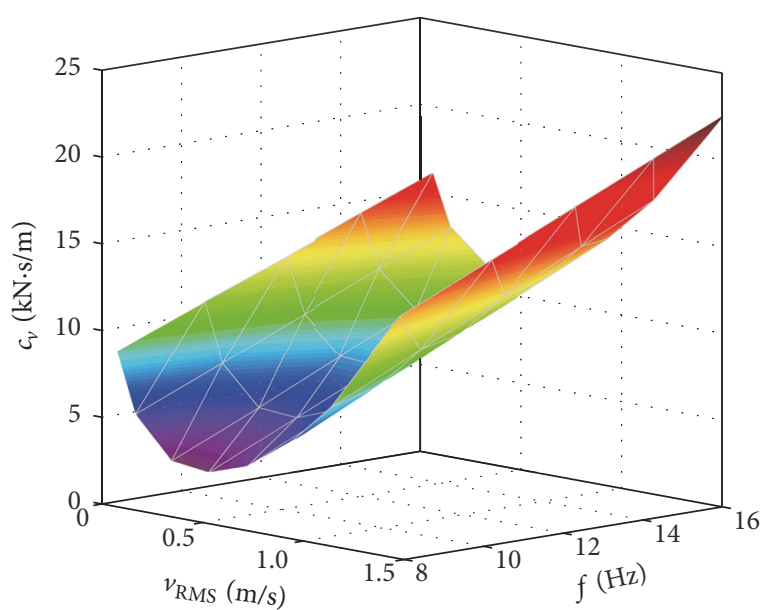

(d)

FIGURE 6: The optimized results of damping control gain.

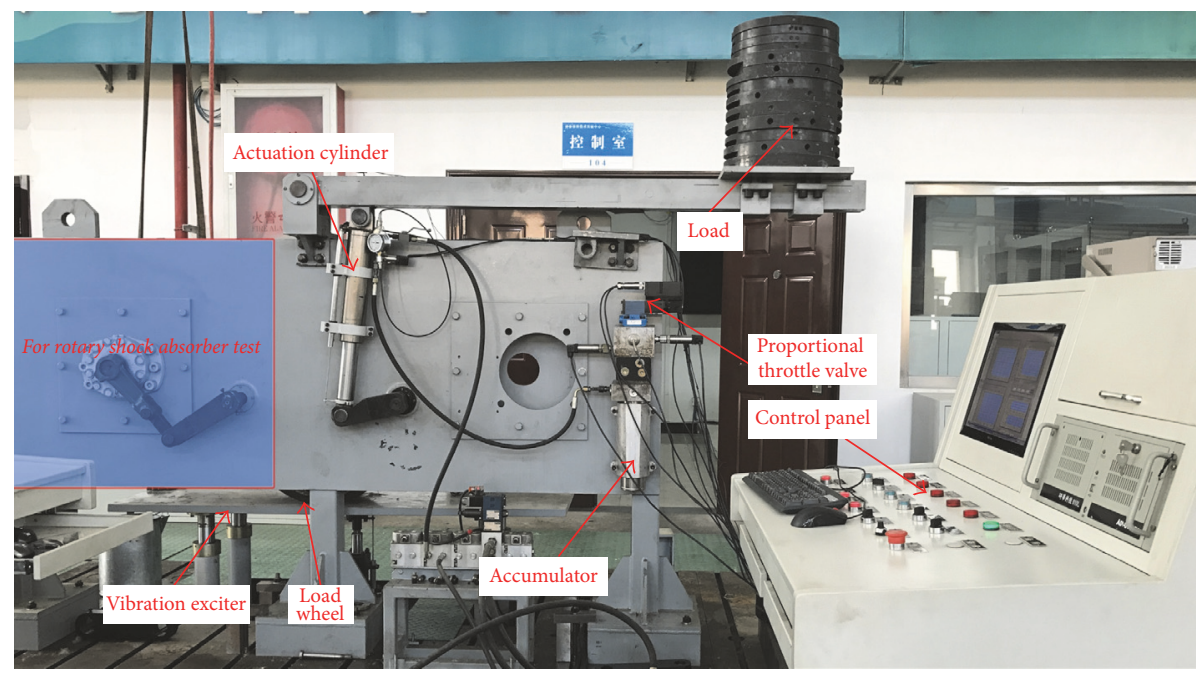

Figure 7: Test rig of hydropneumatic suspension. 
TABLE 5: The input disturbances estimation and the optimization results.

\begin{tabular}{|c|c|c|c|}
\hline \multirow{2}{*}{ Driving conditions } & \multicolumn{3}{|c|}{ Periods } \\
\hline & $0 \sim 5 \mathrm{~s}$ & $5 \sim 10 \mathrm{~s}$ & $10 \sim 15 \mathrm{~s}$ \\
\hline Road class & D class & F class & H class \\
\hline Speed $v /\left(\mathrm{km} \cdot \mathrm{h}^{-1}\right)$ & 60 & 30 & 5 \\
\hline RMS value of disturbance (measured/estimated) $/\left(\mathrm{m} \cdot \mathrm{s}^{-1}\right)$ & $0.48 / 0.46$ & $0.39 / 0.38$ & $0.27 / 0.26$ \\
\hline Estimated frequency $(\mathrm{Hz})$ & 9.5 & 1.8 & 0.8 \\
\hline Control mode & Adaptive & Semiactive & Semiactive \\
\hline Weighting factor $\left(\rho_{b}, \rho_{s}, \rho_{w}\right)$ & $(0.3,0.3,0.4)$ & $(0.7,0.2,0.1)$ & $(0.8,0.15,0.05)$ \\
\hline \multirow{3}{*}{ Damping coefficient (kNs/m) } & & $c_{\mathrm{sky}}=15.1$ & $c_{\mathrm{sky}}=16.2$ \\
\hline & $c_{v}=5.12$ & $c_{\text {ground }}=4.52$ & $c_{\text {ground }}=3.58$ \\
\hline & & $c_{\text {hybrid }}=8.75$ & $c_{\text {hybrid }}=6.71$ \\
\hline
\end{tabular}

TABLE 6: Comparison of suspension performances of different control strategies (hybrid/skyhook/ground hook/passive).

\begin{tabular}{lccr}
\hline Performances & D road, $60 \mathrm{kmph}$ & Driving conditions \\
& $(0 \sim 5 \mathrm{~s})$ & $\begin{array}{c}\text { F road, } 30 \mathrm{kmph} \\
(5 \sim 10 \mathrm{~s})\end{array}$ & $\begin{array}{c}\mathrm{H} \mathrm{road,} 5 \mathrm{kmph} \\
(10 \sim 15 \mathrm{~s})\end{array}$ \\
\hline$a_{\mathrm{BRMS}}\left(\mathrm{m} \cdot \mathrm{s}^{-2}\right)$ & $4.92 / 5.35 / 5.72 / 4.65$ & $4.85 / 4.44 / 7.63 / 6.47$ & $2.86 / 2.59 / 4.49 / 4.0$ \\
$F_{\mathrm{DRMS}}(\mathrm{kN})$ & $6.57 / 9.28 / 8.76 / 7.87$ & $4.96 / 5.13 / 3.63 / 4.7$ & $3.22 / 3.27 / 2.42 / 2.92$ \\
$S_{\mathrm{RMS}}(\mathrm{mm})$ & $13.1 / 20.1 / 19.8 / 15.1$ & $29.8 / 30.6 / 22.6 / 27.9$ & $46.1 / 47.1 / 37.7 / 42.4$ \\
\hline
\end{tabular}

strategies under different disturbances. The statistics of the suspension performance are presented in Table 6 and the normalized performances which are the ratios of the statistics to those of the passive suspension are shown in Figure 12.

In the time interval of $0 \sim 5 \mathrm{~s}$, as the disturbance frequency exceeded the adjustment bandwidth of the suspension damping, the self-adaptive control mode was adopted. Furthermore, since the disturbance frequency was relatively close to the natural frequency of the road wheel and the disturbance velocity was relatively large, greater emphasis was placed on suppressing the dynamic load on the wheel and suspension stroke. As seen from Figure 12(a), the sprung mass acceleration deteriorated only about $5.8 \%$ in comparison to the passive suspension; however the wheel dynamic load and the stroke were improved by about $16.5 \%$ and $13.2 \%$ respectively. The sprung acceleration, dynamic load, and suspension stroke of the skyhook and groundhook strategies all worsened, mainly due to the time-lag effect during the tuning phase of damping under high-frequency excitation.

In the time intervals of $5 \sim 10 \mathrm{~s}$ and $10 \sim 15 \mathrm{~s}$, since the disturbance frequency was relatively low, close to the resonant frequency of the sprung mass, and the disturbance velocities were in the mid to low range, the emphasis was on the improvement of ride comfort. The adopted control strategy was therefore the semiactive control. It was found that the sprung mass acceleration was significantly improved by about 25.1\% (5 10 s) and 28.5\% (10 15s) in comparison to passive suspension systems, while the wheel dynamic load as well the suspension stroke became slightly worse. The wheel dynamic load increased by about 5.5\% (5 10 s) and 10.2\% (10 15 s) and the suspension stroke increased by about $6.8 \%(5 \sim 10 \mathrm{~s})$ and

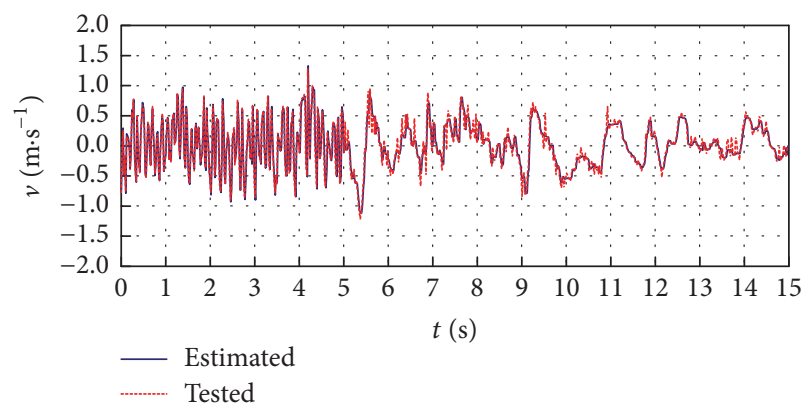

FIGURE 8: The typical disturbance input and its estimation.

$8.7 \%(10 \sim 15 \mathrm{~s})$, respectively. In the test of the above low frequency $(0 \sim 2 \mathrm{~Hz})$ excitations, as seen from Figures $12(\mathrm{~b})$ and $12(\mathrm{c})$, the $a_{\mathrm{BRMS}}$ of the hybrid strategy is higher than that of the skyhook. As the human body is the least sensitive to the vertical vibration in this frequency range according to the ISO 2631, the little increasing of vertical acceleration could not be felt.

In summary, the semiactive hybrid control strategy is unable to achieve the same effect as skyhook control alone with respect to ride comfort, nor the same ride safety features as groundhook alone. However, for the real driving condition which contains different kinds of disturbances, the hybrid strategy outperforms the others with respect to the overall performances by taking advantage of the adaptability of the suspension control algorithm and damping control gain scheduling under different road excitations. 

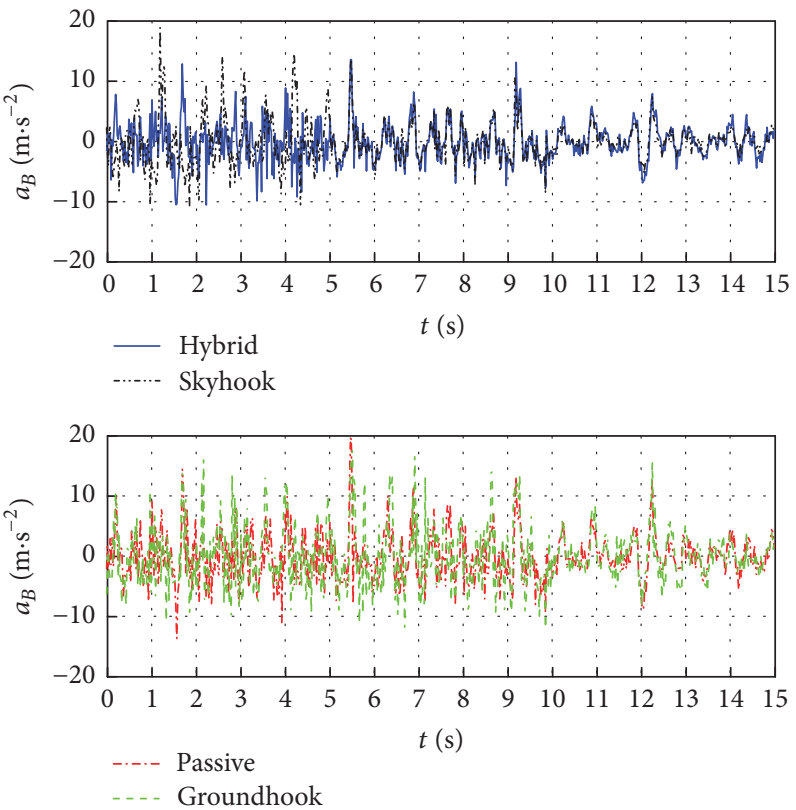

FIGURE 9: The sprung mass acceleration comparison.
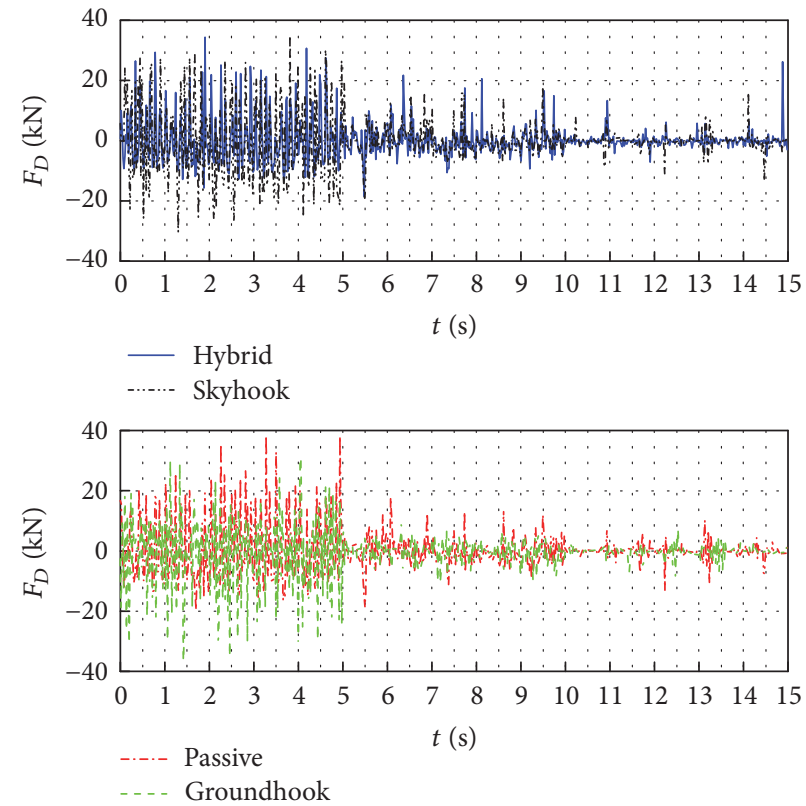

FIgURE 10: Comparison of the dynamic load of the wheel.

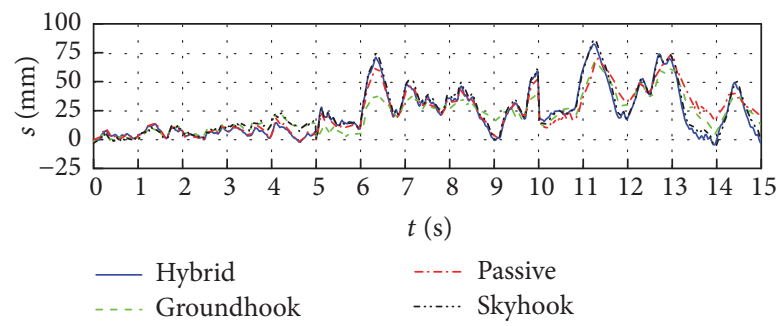

FIGURE 11: Comparison of the suspension stroke. 


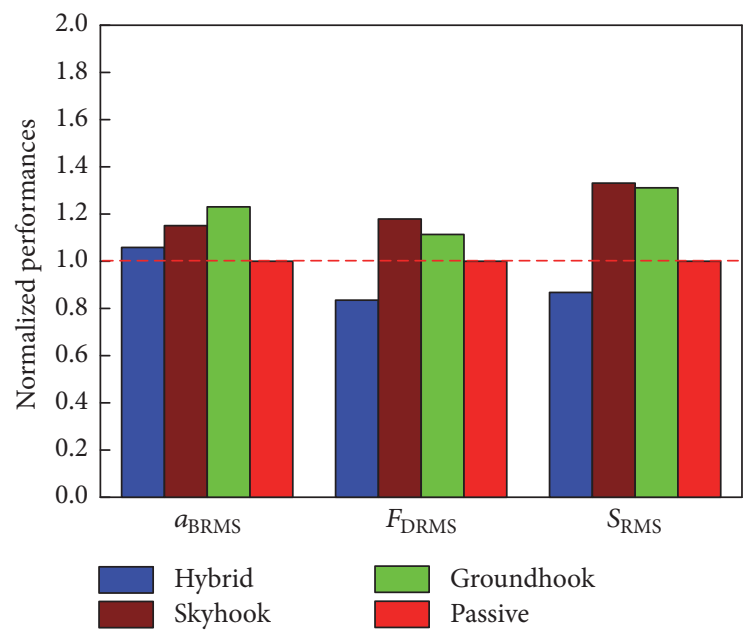

(a) $\mathrm{D}$ road, $60 \mathrm{kmph}$

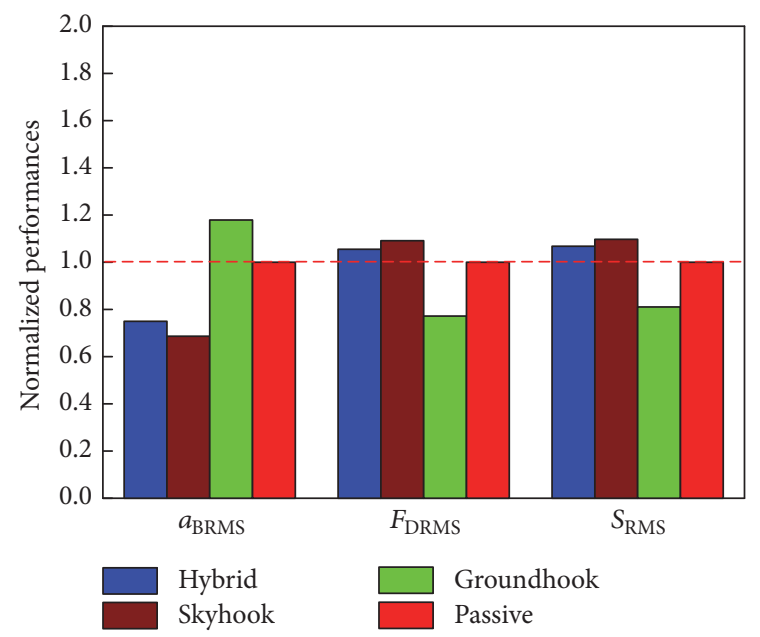

(b) F road, $30 \mathrm{kmph}$

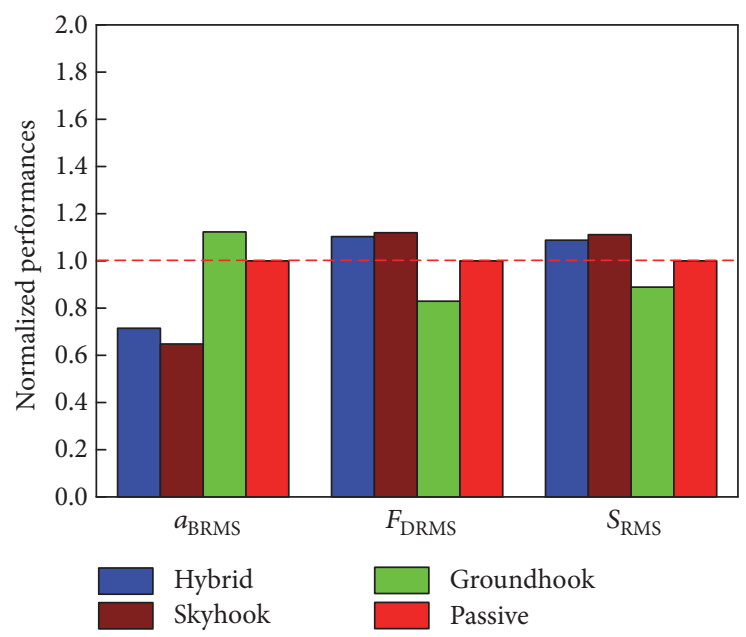

(c) $\mathrm{H}$ road, $5 \mathrm{kmph}$

FIGURE 12: Comparison of normalized performances of different control strategies.

\section{Conclusions}

This paper proposed a semiactive and self-adaptive hybrid control strategy for hydropneumatic suspensions for tracked vehicles based on road disturbance identification, and presented an experimental study using a test rig. The conclusions are as follows.

(1) Using an offline PSO algorithm, the optimized damping control gains of the hydropneumatic suspension under various disturbances can be obtained.

(2) Based on the two-DOF kinematic relations of the order-reduced suspension model and frequency zero-crossing detection method, the comprehensive index of the suspension performances and expressions of disturbance velocity and frequency can be established, and accurate identification of the disturbance can be realized.

(3) The results of the test rig experimental study based on four typical control strategies indicates that the proposed semiactive self-adaptive hybrid control strategy is capable of performing adjustments on the control mode and control gain according to the disturbance characteristics. Moreover, the strategy is capable of enhancing the adaptability of the suspension system under different riding conditions and achieves a good trade-off between ride comfort and ride safety.

\section{Conflicts of Interest}

The authors declare that there are no conflicts of interest regarding the publication of this manuscript.

\section{References}

[1] S. Ryu, Y. Park, and M. Suh, "Ride quality analysis of a tracked vehicle suspension with a preview control," Journal of Terramechanics, vol. 48, no. 6, pp. 409-417, 2011.

[2] K.-H. Guo, J.-K. Sui, and Y.-H. Guo, "Semi-active control method for a high-speed railway vehicle lateral damper based on skyhook and groundhook hybrid damping," Journal of Vibration \& Shock, vol. 32, no. 2, pp. 18-22, 2013. 
[3] X. Gao, L. Gu, J. Guan, Y. Li, R. Liu, and Y. Xing, "Research on in-arm semi-active hydro-pneumatic suspension of tracked vehicle," Journal of Vibration, Measurement and Diagnosis, vol. 35, no. 5, pp. 968-972, 2015.

[4] J. Emura, "Development of the semi-active suspension system based on the sky-hook damper theory," Society of Automative Engineers, pp. 17-26, 1994.

[5] K. Yi, "Observer-based control of vehicle semi-active suspensions," in Proceedings of the Institution of Mechanical Engineers Part D: Journal of Automobile Engineering, pp. 531-543, 1999.

[6] M. Ahmadian and C. A. Pare, "A quarter-car experimental analysis of alternative semiactive control methods," Journal of Intelligent Material Systems and Structures, vol. 11, no. 8, pp. 604-612, 2000.

[7] J. C. Tudo'n Marti'nez, J. J. Lozoya-Santos, C. A. Vivas, R. Morales-Menendez, and R. Ramirez-Mendoza, "Model-free controller for a pick-up semi-active suspension system," in Proceedings of the ASME's International Mechanical Engineering Congress and Exposition, pp. 67-76, Texas, TX, USA, 2012.

[8] S. Choi, H. Lee, and Y. Park, " $H_{\infty}$ control performance of a fullvehicle suspension featuring magnetorheological dampers," Vehicle System Dynamics, vol. 38, no. 5, pp. 341-360, 2002.

[9] J. Wang, D. A. Wilson, W. Xu, and D. A. Crolla, "Active suspension control to improve vehicle ride and steady-state handling," in Proceedings of the 44th IEEE Conference on Decision and Control, and the European Control Conference, CDC-ECC '05, pp. 1982-1987, December 2005.

[10] M. Chadli, A. El Hajjaji, and A. Rabhi, "Ho Observer-based robust multiple controller design for vehicle lateral dynamics," in Proceedings of the 2010 American Control Conference, ACC 2010, pp. 1508-1513, July 2010.

[11] J. Yoon, W. Cho, J. Kang, B. Koo, and K. Yi, "Design and evaluation of a unified chassis control system for rollover prevention and vehicle stability improvement on a virtual test track," Control Engineering Practice, vol. 18, no. 6, pp. 585-597, 2010.

[12] C. Poussot-Vassal, C. Spelta, O. Sename, S. M. Savaresi, and L. Dugard, "Survey and performance evaluation on some automotive semi-active suspension control methods: A comparative study on a single-corner model," Annual Reviews in Control, vol. 36, no. 1, pp. 148-160, 2012.

[13] C. Crivellaro, "Robust semi-active suspension system control for pickup truck," in Proceedings of the SAE World Congress \& Exposition, vol. 2009.

[14] S. Ikenaga, F. L. Lewis, J. Campos, and L. Davis, "Active suspension control of ground vehicle based on a full-vehicle model," in Proceedings of the American Control Conference, pp. 4019-4024, 2010.

[15] J. Swevers, C. Lauwerys, B. Vandersmissen, M. Maes, K. Reybrouck, and P. Sas, "A model-free control structure for the online tuning of the semi-active suspension of a passenger car," Mechanical Systems and Signal Processing, vol. 21, no. 3, pp. 1422-1436, 2007.

[16] X. M. Dong, M. Yu, Z. Li, C. Liao, and W. Chen, "Neural network compensation of semi-active control for magneto-rheological suspension with time delay uncertainty," Smart Materials and Structures, vol. 18, no. 1, 2009.

[17] J. Guan, L. Gu, and C. Hou, "Adaptive control for semi-active suspension tracked vehicle," Acta Armamentarii, vol. 25, no. 4, pp. 389-393, 2004.

[18] H. Shousong, C. Zhiqiang, and L. Xiangbo, Effect Analysis of the Parameters of Hydro-pneumatic Suspension on the off Wheel
Failure of a Tracked Vehicle, vol. 2, Academy of Armored Forces Engineering, 2017.

[19] U. Solomon and C. Padmanabhan, "Semi-active hydro-gas suspension system for a tracked vehicle," Journal of Terramechanics, vol. 48, no. 3, pp. 225-239, 2011.

[20] T. Nabagło, A. Jurkiewicz, and J. Kowal, "Semi-active Suspension System for 2S1 Tracked Platform in Drive Comfort Improvement Application," in Innovative Simulation Systems, vol. 33 of Studies in Systems, Decision and Control, pp. 259-275, Springer International Publishing, 2016.

[21] W. G. Ata and A. M. Salem, "Semi-active control of tracked vehicle suspension incorporating magnetorheological dampers," Vehicle System Dynamics, vol. 55, no. 5, pp. 626-647, 2017.

[22] H. Bolandhemmat, C. M. Clark, and F. Golnaraghi, "Development of a systematic and practical methodology for the design of vehicles semi-active suspension control system," Vehicle System Dynamics, vol. 48, no. 5, pp. 567-585, 2010.

[23] I. Youn, M. A. Khan, N. Uddin, E. Youn, and M. Tomizuka, "Road disturbance estimation for the optimal preview control of an active suspension systems based on tracked vehicle model," International Journal of Automotive Technology, vol. 18, no. 2, pp. 307-316, 2017.

[24] L. H. Nguyen, K.-S. Hong, and S. Park, "Road-frequency adaptive control for semi-active suspension systems," International Journal of Control, Automation, and Systems, vol. 8, no. 5, pp. 1029-1038, 2010.

[25] Y. Wuhui, Road Frequency \& Vehicle Load Adaptive Semi-Active Suspension Control Strategy, Jilin University, Jilin, China, 2014.

[26] FunctionBay, RecurdynV8R3, 2014 http://www.recurdyn.com.

[27] LMS Imagine.Lab, AMESim14.0, 2015 http://www.amesim.com.

[28] H. M. Gomes, "Multi-objective optimization of quarter car passive suspension design in the frequency domain based on PSO," Engineering Computations, vol. 33, no. 5, pp. 1422-1434, 2016.

[29] J. Lu, "A frequency-adaptive multi-objective suspension control strategy," Journal of Dynamic Systems, Measurement, and Control, vol. 126, no. 3, pp. 700-707, 2004.

[30] ISO 2631-1, "International organization of standardization. Mechanical vibration and shock - evaluation of human exposure to whole body vibration. Part 1: General requirement," 1997.

[31] R. Xie, G. Yang, and L. Xu, "Dynamic analysis of multi-body system for rigid-flexible coupling self-propelled gun on move," Journal of Nanjing University of Science and Technology, vol. 38, no. 5, pp. 588-592, 2014.

[32] D. Faqian, Dynamics of Suspension System of Tracked Armored Vehicle, National Defense Industry Press, 2004.

[33] Z. Changcheng, Vehicle Suspension Design and Theory, Peking University Press, 2011.

[34] Y.-C. Qin, M.-M. Dong, F. Zhao, and L. Gu, "Suspension semiactive control of vehicles based on road profile classification," Journal of Northeastern University, vol. 37, no. 8, pp. 1138-1143, 2016.

[35] H.-B. Jiang, J.-T. Geng, X.-L. Zhang, and T. Wang, "Study on co-simulation of vehicle suspension system employing inerter based on virtual protoype model," Journal of Vibration and Shock, vol. 29, no. 12, pp. 221-223, 2010.

[36] E. Guglielmino, T. Sireteanu, C. W. Stammers, G. Ghita, and M. Giuclea, Semi-Active Suspension Control: Improved Vehicle Ride and Road Friendliness, Springer, London, UK, 2008. 


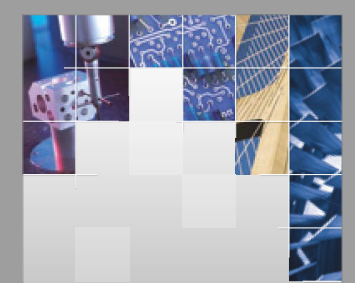

\section{Enfincering}
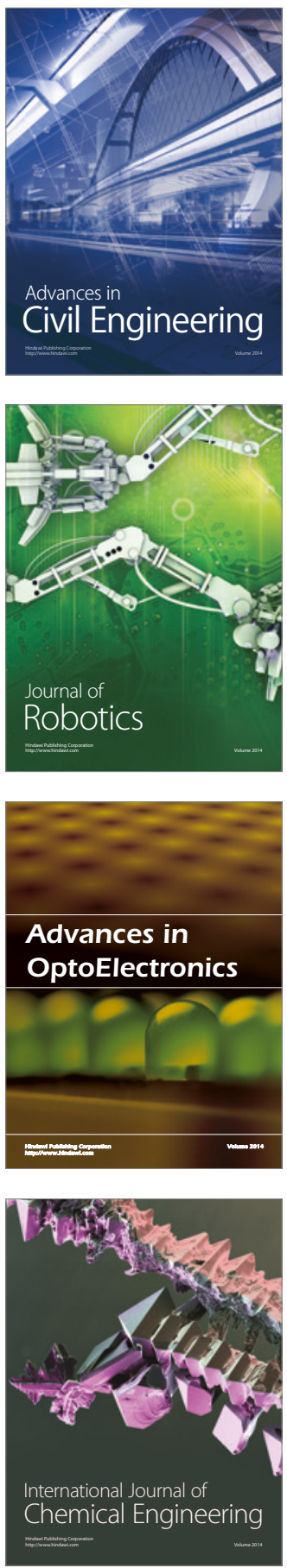

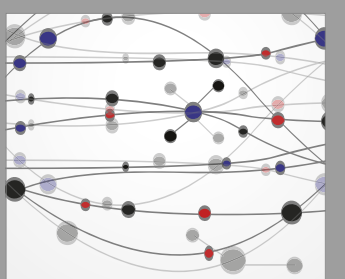

The Scientific World Journal

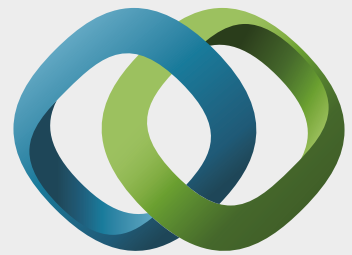

\section{Hindawi}

Submit your manuscripts at

https://www.hindawi.com
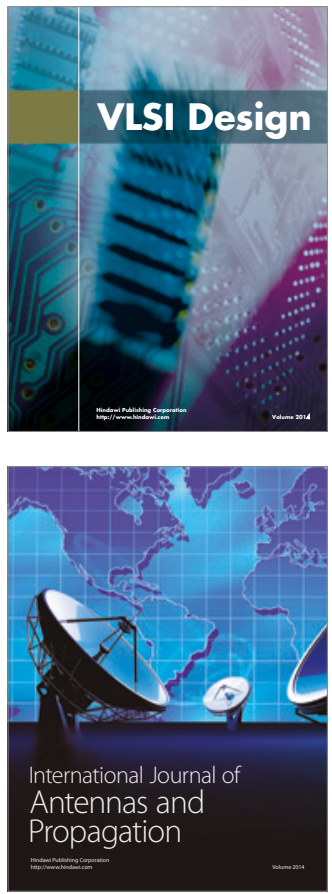

\section{Rotating}

Machinery
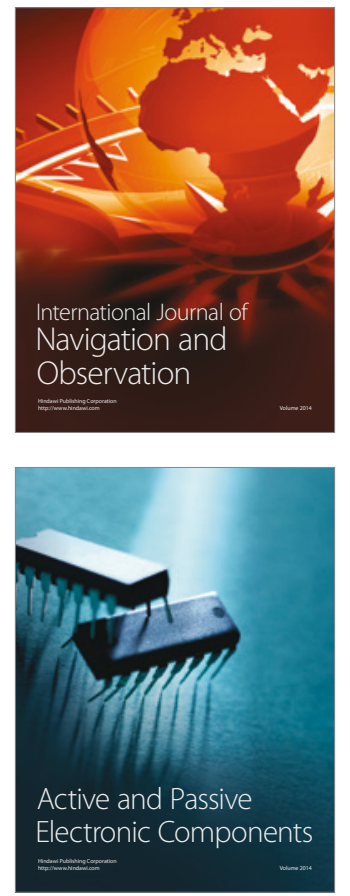
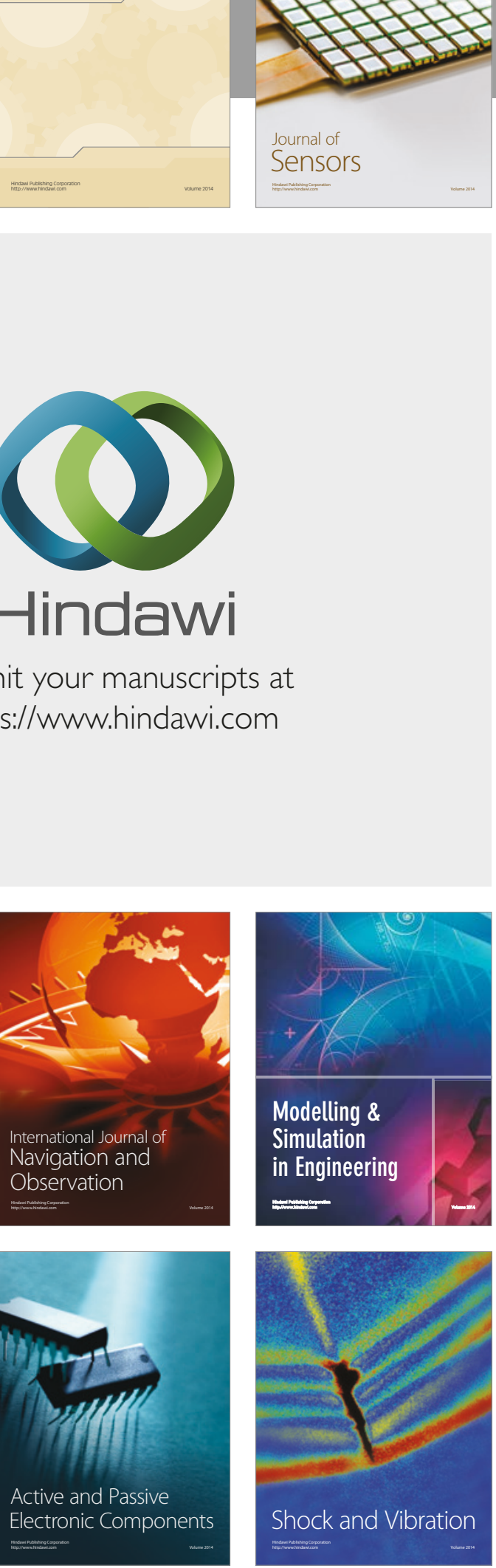
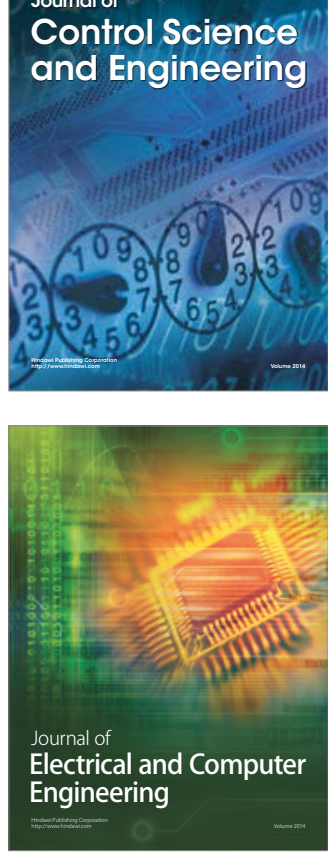

Distributed

Journal of

Control Science

and Engineering
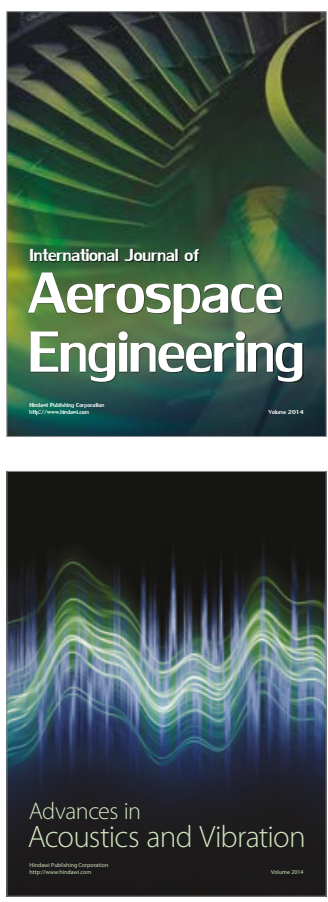

Sensor Networks 